\title{
Contribution of Proton Magnetic Resonance Spectroscopy to the Evaluation of Children with Unexplained Developmental Delay
}

\author{
ERNST MARTIN, MARTIN KELLER, SUSANNE RITTER, REMO H. LARGO, \\ THORSTEN THIEL, AND THOMAS LOENNEKER
}

Neuroradiology and MR Center [E.M.], Center for Growth and Development [S.R., R.H.L.], MR Center

[M.K., T.T., T.L.], University Children's Hospital, CH-8032 Zurich, Switzerland

\begin{abstract}
Developmental delay (DD) in children is a common socioeconomic problem with a prevalence of $1-2 \%$. The cause of DD in children is often unknown, and magnetic resonance imaging plays an important role in evaluating children with DD, estimating long-term prognosis, and guiding therapeutic options. The aim of our study on children with DD was to elucidate 1) whether magnetic resonance spectroscopy (MRS) reveals abnormalities in cerebral metabolism and 2) whether there is a correlation between the cognitive performance and the concentration of brain metabolites, especially $\mathrm{N}$-acetylaspartate (NAA), named in the literature a neuronal marker. Using proton MRS of deep gray and central white matter, we measured concentrations of brain metabolites in 48 children, who were aged 1 mo to $13 \mathrm{y}$ and had unexplained DD [developmental quotient (DQ) between $<50$ and 85] and normal magnetic resonance imaging examinations, and compared them with those of 23 age-matched normal control children. Children with DD were divided into three groups: mild (DQ 76-85), moderate (DQ 51-75), and severe (DQ <50). We found no significant differences in metabolite concentrations, neither among the three groups of children with DD nor between
\end{abstract}

\section{ABSTRACT}

patients and age-matched normal control children. Independent of the degree of mental retardation, the NAA concentrations of handicapped patients and normal children were comparable. We conclude that 1) brain metabolites, especially NAA, in children with unexplained DD are within normal limits, and 2) in most cases, proton MRS adds little information concerning cause of unexplained DD. (Pediatr Res 58: 754-760, 2005)

Cho, choline
Cr, creatine
DD, developmental delay
DQ, developmental quotient
Gln, glutamine
Glu, glutamate
mIns, myo-inositol
MRI, magnetic resonance imaging
MRS, magnetic resonance spectroscopy
NAA, N-acetylaspartate
NAAG, N-acetyl-aspartylglutamate

established guidelines regarding the evaluation of children with mental retardation $(3,4)$. An important aspect in the search of possible causes for the child's delay is the characterization of the type of DD, e.g. global delay or isolated forms, because they afford different evaluation strategies (5-7). Global delay is defined as significant delay in two or more of the following domains: motor (gross/fine), speech/language, cognition, personal/social, and activities of daily living. There is general agreement that magnetic resonance imaging (MRI) plays an important role in the evaluation of children with DD in certain clinical settings (8) and that MRI seems to be more sensitive than computed tomography, with abnormalities found in 48.6$65.5 \%$ of children with global delay (9-12). Nevertheless, there is an ongoing discussion about the indication of MRI, especially in children with global DD (13).

In recent years, investigators have used proton $(1 \mathrm{H})$ and phosphorus (31P) magnetic resonance spectroscopy (MRS) to
Received September 16, 2004; accepted February 15, 2005.

Correspondence: Ernst Martin, M.D., Neuroradiology \& MR Center, Department of Diagnostic Imaging, University Children's Hospital, Steinwiesstrassse 75, CH-8032 Zurich, Switzerland; e-mail: Ernst.Martin@kispi.unizh.ch.

DOI: 10.1203/01.PDR.0000180559.29393.BE 
study cerebral metabolism during normal brain maturation and myelination (14-17). Neurospectroscopy has been demonstrated to be of value in evaluating neurodegenerative, inflammatory, and metabolic diseases $(18,19)$; neuropsychiatric disorders (20); hypoxic-ischemic brain injury (9,21-23); and epilepsy (24). Using $1 \mathrm{H}-\mathrm{MRS}$, we gain quantitative information from various cerebral metabolites, such as amino acids [N-acetylaspartate (NAA), alanine, and glutamate (Glu)], amines [glutamine (Gln), choline (Cho), and creatine $(\mathrm{Cr})$ ], sugars [myo-inositol (mIns) and glucose], and compounds involved in high-energy metabolism ( $\mathrm{Cr}$ and lactate). Beyond the age of $3 \mathrm{y}$, the signal from acetyl resonances at $\sim 2.0 \mathrm{ppm}$ is most prominent in the brain spectrum from cerebral gray matter as well as from white matter (25). It belongs predominantly to NAA, with small contributions from $\mathrm{N}$-acetylaspartylglutamate (NAAG) (26). NAA is almost exclusively present in the CNS (27), specifically in pyramidal neurons, dendrites, and axons $(28,29)$, and therefore is called a neuronal marker, but NAA is also found in oligodendrocyte type 2 astrocyte progenitor cells, in immature (30) and in mature oligodendrocytes (31), and there is now increasing evidence that NAA can be used only as a surrogate of viable neuronal tissue under certain circumstances (32). Moreover, it was reported recently that the cerebral concentration of NAA is correlated with mental development (33) and with cognitive performance (34) and that a decrease of NAA in the aging brain might be correlated with altered brain functions (35).

The aim of this study was to further elucidate this point and to evaluate whether MRS can add valuable information to neuroimaging of children with DD by revealing abnormalities in cerebral metabolism. We asked the question whether there is a correlation between the cognitive performance and the concentration of brain metabolites, especially NAA, in children with DD of unknown origin. More specific, we were interested to know whether children with significant unexplained developmental delay (IQ <75) have lower brain levels of NAA, when compared with age-matched control subject, as reported earlier $(36,37)$.

\section{METHODS}

Patients. Forty-eight children who were aged 1 mo to 13 y (19 girls, 29 boys; mean $\pm \mathrm{SD} 3.6 \pm 2.9$ y) and undergoing a neuroradiologic work-up because of mental retardation of unknown origin but without progressive clinical course and no evidence of metabolic abnormalities were enrolled in this study. Patients with recognizable lesions on MRI, cerebral palsy, chromosome abnormalities, or other neurologic or degenerative diseases were excluded. MRI included axial T1 or 3D T1-weighted images; axial, sagittal, and coronal T2-weighted images; and coronal fluid-attenuated inversion recovery images. The developmental quotient (DQ) was calculated in all children (see below). There were 19 girls and 29 boys; 12 children had severe mental retardation (DQ $<50), 24$ children had moderately severe mental retardation (DQ 51-75), and 12 children had only minor mental retardation (DQ 76-85). In addition, 23 age-matched children (eight girls, 15 boys; age range 1 mo-12 $\mathrm{y}$; mean \pm SD $3.2 \pm 3.2$ y) with normal DQ $(>95)$ and normal MRI served as control subjects. They received a brain MRI examination for noncerebral or nonneurologic indications. All children who were younger than $6 \mathrm{y}$ were sedated.

The MRI examinations and psychomotor testing in normal children were carried out after informed consent has been obtained from the patients and/or their parents. The study was approved by the ethics committee of the University Children's Hospital Zurich according to the Declaration of Helsinki.

Psychomotor testing. All children were examined at the University Children's Hospital Zurich by two pediatricians (S.R. and R.H.L.) who were experienced in developmental neurology. Age-appropriate developmental tests (Denver, Griffiths, Bayley, and Kaufman) were used to evaluate the DQ or IQ of the patients and to subdivide them into three groups: severe (DQ or IQ $<50$ ), moderate (DQ or IQ 50-75), or mild (DQ or IQ $>75$ ).

To classify the DD, we used the SD score of the DQ

$$
S D S \text { of } D Q=\frac{D Q / I Q-D Q / I Q_{\text {norm }}}{S D_{\text {norm }}}
$$

where $D Q / I Q$ is the mean DQ coefficient, $\overline{D Q / I Q_{\text {norm }}}$ is the mean DQ coefficient [based on the norm population of the "Zürcher Longitudinalstudie" (38)], and $S D_{\text {norm }}$ is the SD of this normative DQ coefficient.

Proton MRS. Quantitative, water-suppressed 1H-MRS (point-resolved spectroscopy) was performed on a 2Tesla whole-body MR system (Tomikon S200A; Bruker Medical Systems, Fällanden, Switzerland) using a standard quadrature head coil. Depending on the protocol of the routine MR examination, $6 \mathrm{~mL}$ volume voxels were positioned in frontoparietal white matter ( $10 \%$ average partial volume from the cortical gray matter) and/or deep gray matter (20\% average partial volume from the thalamus; Figs. 1 and 2). In 55 children (21 control subjects, 34 patients), only one of these two locations could be measured. Short echo time fully relaxed spectra with a TE of $30 \mathrm{~ms}$ were acquired using repetition times of $6000 \mathrm{~ms}$. Sixty-four scans were averaged at a bandwidth of $2 \mathrm{kHz}$. Partial volume correction for tissue water content and contamination of cerebrospinal fluid from the subarachnoid space or the ventricles was done according to Kreis et al. (39). Chemical shifts were set using the signal of NAA. The MR spectra were analyzed using the LC-Model software package (40) with the unsuppressed water resonance as an internal reference (39). The tissue water content was estimated in-house as $0.82 \mathrm{M}$ (gray matter) and $0.72 \mathrm{M}$ (white matter) in adults and $0.9 \mathrm{M}$ (gray and white matter) in neonates. Thus, a mean concentration of $0.8 \mathrm{M}$ was used for the water scaling. The remaining error as a result of the age-dependant differences remains constant within the age groups and therefore can be
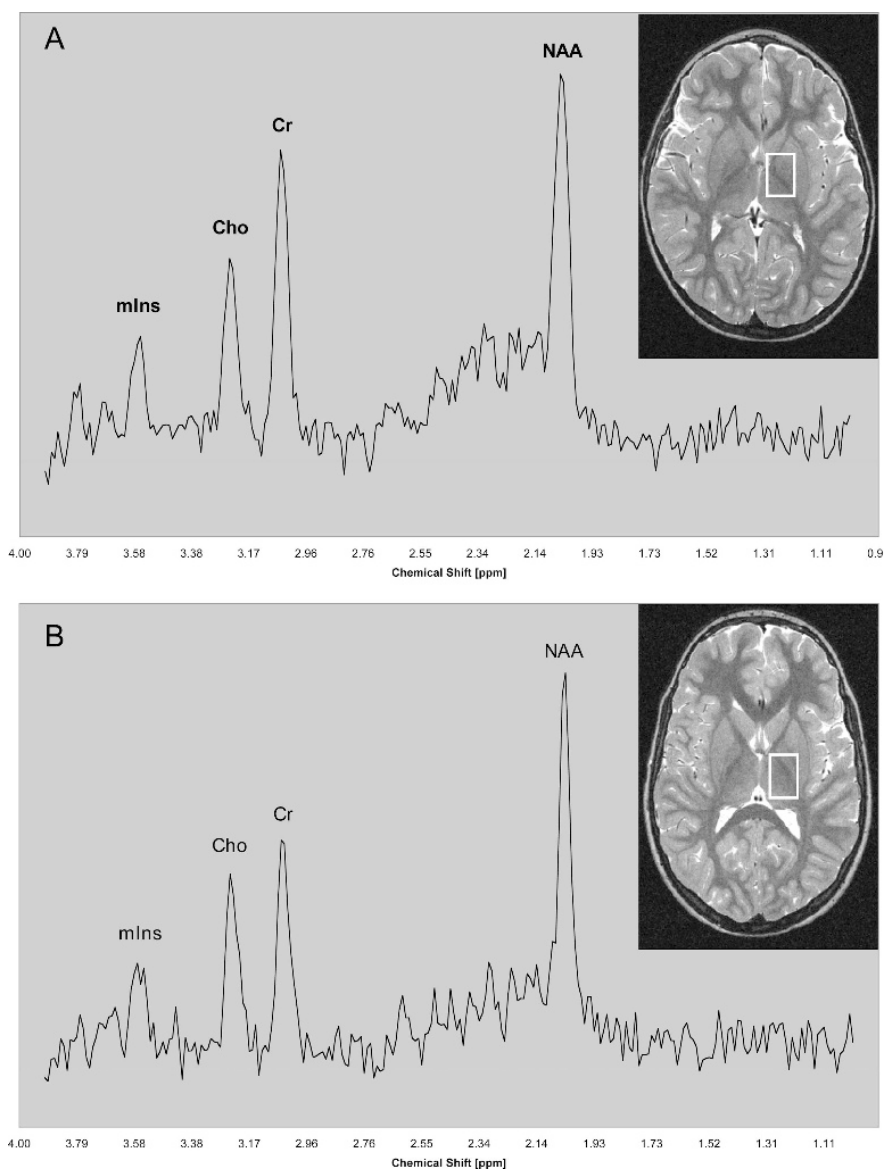

Figure 1. Comparison of patient and control spectra taken from the deep gray matter. (A) Unfiltered short $\mathrm{TE}{ }^{1} \mathrm{H}$-spectrum from a 4.2-y-old healthy child: NAA $10.75 \mathrm{mM}$, Cho $1.59 \mathrm{mM}$, Cr $8.00 \mathrm{mM}$, mIns $3.10 \mathrm{mM}$. (B) Unfiltered short TE ${ }^{1} \mathrm{H}$-spectrum from a 4.7 -y-old child with severe mental retardation (DQ 45): NAA $11.91 \mathrm{mM}$, Cho $1.63 \mathrm{mM}$, Cr $7.71 \mathrm{mM}$, mIns $4.90 \mathrm{mM}$. 

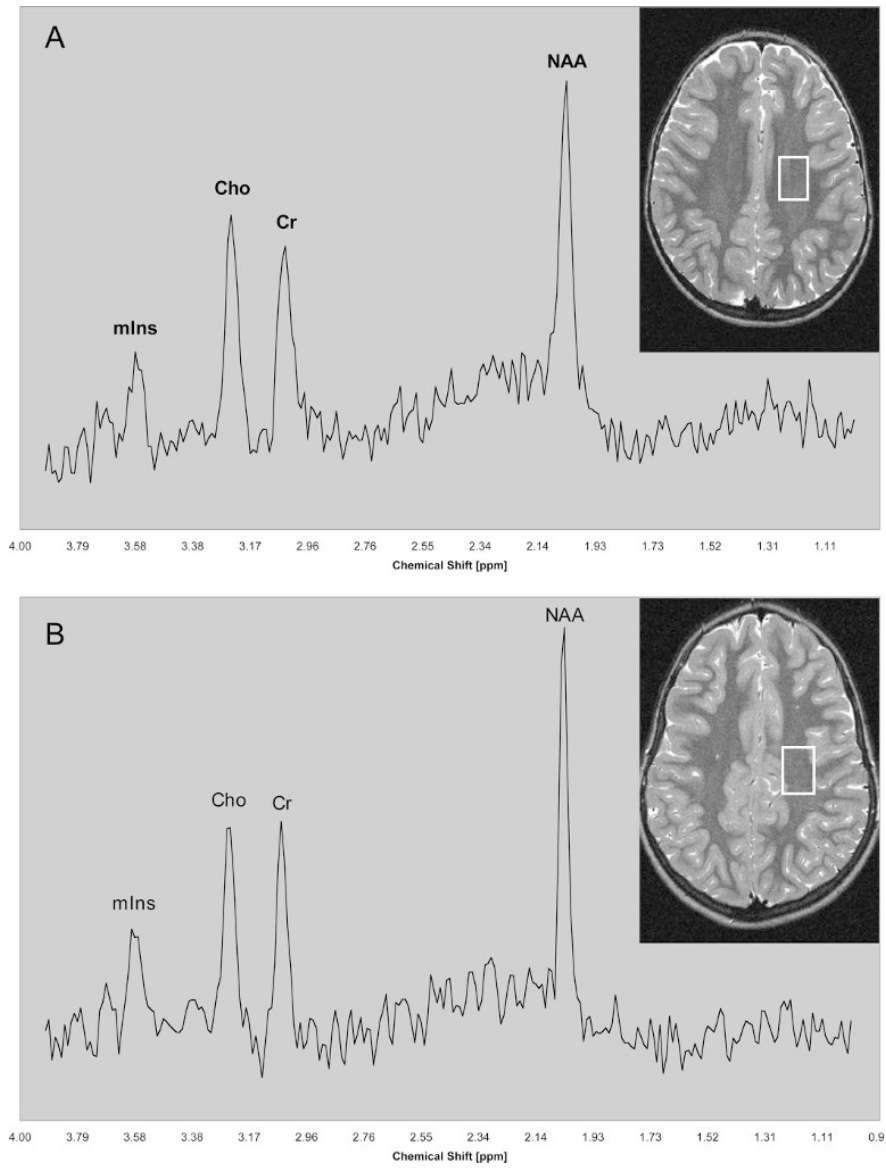

Figure 2. Comparison of patient and control spectra taken from the central white matter. (A) Unfiltered short TE ${ }^{1} \mathrm{H}$-spectrum from a 4.2-y-old healthy child: NAA $10.23 \mathrm{mM}$, Cho $2.06 \mathrm{mM}$, Cr $6.21 \mathrm{mM}$, mIns $4.30 \mathrm{mM}$. $(B)$ Unfiltered short TE ${ }^{1} \mathrm{H}$-spectrum from a 4.7 -y-old child with severe mental retardation (DQ 45): NAA $9.70 \mathrm{mM}$, Cho $1.60 \mathrm{mM}$, Cr $6.43 \mathrm{mM}$, mIns 4.60 $\mathrm{mM}$.

neglected. The calibration of the basis spectra of LC-Model, including all MR-visible physiologic metabolites, was achieved using an external phantom as standard consisting of a solution of $50 \mathrm{mM} \mathrm{Cr}$. A nonparametric bivariate correlation analysis (Kendall-Tau-b) was carried out in SPSS (SPSS Inc., Chicago, IL) for testing age and group effects between children with DD and normal control children.

\section{RESULTS}

Figures 1 and 2 display typical short echo-time pointresolved spectroscopy spectra from a healthy child and from an age-matched patient with mental retardation for deep gray matter and central white matter, respectively. The mean, SD, and median concentration values (50th percentiles) of total NAA, mIns, Cr, and Cho as well as the metabolite ratios $\mathrm{NAA} / \mathrm{Cr}$, mIns/Cr, and $\mathrm{Cho} / \mathrm{Cr}$ from the 23 normal healthy children and from the 48 children with DD are listed in Table 1. Normative, age-dependent, regional concentrations of brain metabolites ranging from infancy to adulthood have been published by Powels et al. (17) and are in good agreement with the results obtained from our control group using quantitative proton MRS.

The median concentrations of NAA in deep gray matter were 10.3, 9.4, 9.8, and $10.4 \mathrm{mM}$ for normal control children and for the children with mild, moderate, and severe DD, respectively. Similarly, the respective median NAA concentrations for central white matter were 9.3, 10.0, 10.4, and 11.2 $\mathrm{mM}$. The concentrations of Gln/Glu are not listed because they are unreliable (SD in LC model $>20 \%$ ) without applying special spectral editing (41). No lactate was found in any of the spectra.

With the use of a nonparametric correlation analysis, the metabolite concentrations and ratios of the normal individuals and of the children with mental retardation were tested for age and group effects. This yielded correlation coefficients and two-tailed significance levels of the different brain metabolites for gray and white matter (Table 2).

NAA (correlation coefficient, $\mathrm{cc}=0.38, p=0.001$ ) and $\mathrm{NAA} / \mathrm{Cr}(\mathrm{cc}=0.31, p=0.005)$ showed the expected positive correlation with age in the deep gray matter spectra. All other metabolites did not reach significance in deep gray matter. The central white matter spectra yielded significant positive correlations $(p<0.01)$ with age for NAA $(\mathrm{cc}=0.50, p<0.000)$, $\mathrm{NAA} / \mathrm{Cr}(\mathrm{cc}=0.29, p=0.003)$, and mIns $(\mathrm{cc}=0.30, p=$ $0.003)$. However, the slight increase of mIns with age is still within the range of published age-dependent norm values (17).

A significant group effect was found only for $\mathrm{mIns} / \mathrm{Cr}$ ( $\mathrm{cc}=$ $0.33, p=0.009)$ in deep gray matter. This is due to the insignificant increase of mIns and insignificant decrease of $\mathrm{Cr}$ with the severity of DD and might reflect more the intersubject variability than the effect of DD. NAA ( $\mathrm{cc}=0.28, p=0.012)$ and NAA/Cr ( $\mathrm{cc}=0.25, p=0.021)$ just failed to reach significance at the 0.01 level of the group analysis in central white matter spectra. NAA shows a positive correlation with the severity of the DD, which is in contradiction to the hypothesis that the cerebral concentration of NAA is correlated with mental development (33) and cognitive performance (34). All other metabolites did not show significant correlations between groups.

Figure 3 illustrates box plots of the different brain metabolite concentrations in deep gray matter $(A)$ and central white matter $(B)$ as well as the brain metabolite ratios in deep gray matter $(C)$ and central white matter $(D)$, all grouped according to the severity of DD. Independent of the degree of mental retardation, the metabolite concentrations of all children with DD are comparable with those from the normal cohort. They do not exhibit any group-specific conspicuities.

A regression analysis of the metabolite concentrations versus age of the normal children yielded a linear best fit with mean \pm 2 SD representing the $95 \%$ confident limits for both locations, deep gray and central white matter (Fig. 4). With only a few exceptions, the metabolite concentrations and ratios of the children with DD lie within the normal range $( \pm 95 \%)$.

\section{DISCUSSION}

The most important finding of the present study using quantitative short echo-time proton spectroscopy is that there are no differences in the concentrations of NAA, Cho, mIns, and $\mathrm{Cr}$ between children with DD and age-matched control subjects. For many years, we have incorporated quantitative proton MRS in the neuroradiologic examination of children with unexplained DD because of its potential benefit for de- 
Table 1. Individual concentrations for deep gray matter $(A)$ and central white matter $(B)$ of total $N$-acetylaspartate (NAA), myo-inositol (nIns), creatine $(\mathrm{Cr})$ and choline $(\mathrm{Cho})$ as well as the individual metabolite ratios for deep gray matter $(C)$ and central white matter $(D)$ of total NAA/Cr, mIns/Cr and Cho/Cr.

\begin{tabular}{|c|c|c|c|c|c|}
\hline $\begin{array}{l}\text { (A) Deep Gray Matter } \\
\text { Metabolite Concentrations }\end{array}$ & Group & $\mathrm{N}$ & Mean & Std. Deviation & Median \\
\hline \multirow[t]{4}{*}{ NAA [mmol/l] } & control group & 12 & 10.36 & 1.61 & 10.27 \\
\hline & mild DD & 7 & 10.08 & 1.25 & 9.41 \\
\hline & moderate DD & 13 & 10.04 & 1.63 & 9.80 \\
\hline & severe DD & 6 & 10.48 & 1.35 & 10.38 \\
\hline \multirow[t]{4}{*}{$\mathrm{mIns}[\mathrm{mmol} / \mathrm{l}]$} & control group & 12 & 3.58 & 1.18 & 3.18 \\
\hline & mild DD & 7 & 4.10 & 1.58 & 3.80 \\
\hline & moderate DD & 13 & 4.14 & 0.65 & 4.27 \\
\hline & severe DD & 6 & 4.22 & 1.38 & 4.42 \\
\hline \multirow[t]{4}{*}{$\mathrm{Cr}[\mathrm{mmol} / \mathrm{l}]$} & control group & 12 & 7.94 & 0.75 & 8.11 \\
\hline & mild DD & 7 & 7.42 & 0.69 & 7.53 \\
\hline & moderate DD & 13 & 7.41 & 1.05 & 7.58 \\
\hline & severe DD & 6 & 7.20 & 1.00 & 7.48 \\
\hline \multirow[t]{4}{*}{ Cho $[\mathrm{mmol} / \mathrm{l}]$} & control group & 12 & 1.43 & 0.25 & 1.38 \\
\hline & mild DD & 7 & 1.58 & 0.36 & 1.52 \\
\hline & moderate DD & 13 & 1.41 & 0.25 & 1.42 \\
\hline & severe DD & 6 & 1.37 & 0.28 & 1.39 \\
\hline \multicolumn{6}{|l|}{ (B) Central White Matter } \\
\hline \multirow[t]{4}{*}{$\mathrm{NAA}[\mathrm{mmol} / \mathrm{l}]$} & control group & 13 & 9.54 & 1.18 & 9.29 \\
\hline & mild DD & 10 & 10.03 & 1.38 & 10.01 \\
\hline & moderate DD & 17 & 10.51 & 1.77 & 10.37 \\
\hline & severe DD & 9 & 11.16 & 1.44 & 11.21 \\
\hline \multirow[t]{4}{*}{$\mathrm{mIns}[\mathrm{mmol} / \mathrm{l}]$} & control group & 13 & 4.41 & 1.21 & 3.90 \\
\hline & mild DD & 10 & 4.66 & 0.81 & 4.72 \\
\hline & moderate DD & 17 & 4.01 & 1.08 & 4.23 \\
\hline & severe DD & 9 & 4.82 & 0.70 & 4.60 \\
\hline \multirow[t]{4}{*}{$\mathrm{Cr}[\mathrm{mmol} / \mathrm{l}]$} & control group & 13 & 6.45 & 0.60 & 6.38 \\
\hline & mild DD & 10 & 6.47 & 1.01 & 6.3 \\
\hline & moderate DD & 17 & 6.43 & 0.81 & 6.32 \\
\hline & severe DD & 9 & 6.60 & 0.58 & 6.53 \\
\hline \multirow[t]{4}{*}{ Cho $[\mathrm{mmol} / \mathrm{l}]$} & control group & 13 & 1.71 & 0.30 & 1.65 \\
\hline & mild DD & 10 & 1.60 & 0.21 & 1.63 \\
\hline & moderate DD & 17 & 1.69 & 0.23 & 1.73 \\
\hline & severe DD & 9 & 1.61 & 0.22 & 1.56 \\
\hline \multicolumn{6}{|l|}{ (C) Deep Gray Matter } \\
\hline Metabolite Ratios & Group & $\mathrm{N}$ & Mean & Std. Deviation & Median \\
\hline \multirow[t]{4}{*}{$\mathrm{NAA} / \mathrm{Cr}$} & control group & 12 & 1.30 & 0.15 & 1.29 \\
\hline & mild DD & 7 & 1.36 & 0.13 & 1.29 \\
\hline & moderate DD & 13 & 1.37 & 0.24 & 1.41 \\
\hline & severe DD & 6 & 1.48 & 0.28 & 1.48 \\
\hline \multirow[t]{4}{*}{$\mathrm{mIns} / \mathrm{Cr}$} & control group & 12 & 0.45 & 0.15 & 0.42 \\
\hline & mild DD & 7 & 0.55 & 0.22 & 0.51 \\
\hline & moderate DD & 13 & 0.57 & 0.13 & 0.57 \\
\hline & severe DD & 6 & 0.59 & 0.21 & 0.61 \\
\hline \multirow{4}{*}{$\mathrm{Cho} / \mathrm{Cr}$} & control group & 12 & 0.18 & 0.04 & 0.18 \\
\hline & mild DD & 7 & 0.21 & 0.04 & 0.21 \\
\hline & moderate DD & 13 & 0.19 & 0.03 & 0.19 \\
\hline & severe DD & 6 & 0.19 & 0.03 & 0.18 \\
\hline \multicolumn{6}{|l|}{ (D) Central White Matter } \\
\hline Metabolite Ratios & Group & $\mathrm{N}$ & Mean & Std. Deviation & Median \\
\hline \multirow[t]{4}{*}{$\mathrm{NAA} / \mathrm{Cr}$} & control group & 13 & 1.49 & 0.18 & 1.57 \\
\hline & mild DD & 10 & 1.57 & 0.22 & 1.55 \\
\hline & moderate DD & 17 & 1.64 & 0.26 & 1.72 \\
\hline & severe DD & 9 & 1.69 & 0.18 & 1.69 \\
\hline $\mathrm{mIns} / \mathrm{Cr}$ & control group & 13 & 0.68 & 0.16 & 0.68 \\
\hline & mild DD & 10 & 0.72 & 0.11 & 0.71 \\
\hline & moderate DD & 17 & 0.63 & 0.17 & 0.66 \\
\hline & severe DD & 9 & 0.73 & 0.11 & 0.70 \\
\hline $\mathrm{Cho} / \mathrm{Cr}$ & control group & 13 & 0.27 & 0.05 & 0.27 \\
\hline & mild DD & 10 & 0.25 & 0.04 & 0.26 \\
\hline & moderate DD & 17 & 0.27 & 0.06 & 0.28 \\
\hline & severe DD & 9 & 0.25 & 0.04 & 0.24 \\
\hline
\end{tabular}


Table 2. Non-parametric correlation test statistics for age and group effects including normal children and the three groups of children with DD for $(A)$ deep gray matter and $(B)$ central white matter metabolite concentrations, and for $(C)$ deep gray matter and $(D)$ central white matter.

\begin{tabular}{|c|c|c|c|c|c|c|c|c|}
\hline \multicolumn{2}{|c|}{ (A) Deep Gray Matter } & NAA & mIns & $\mathrm{Cr}$ & Cho & $\mathrm{NAA} / \mathrm{Cr}$ & $\mathrm{mIns} / \mathrm{Cr}$ & $\mathrm{Cho} / \mathrm{Cr}$ \\
\hline \multirow{3}{*}{$\begin{array}{l}\text { Age } \\
(\mathrm{N}=38) \\
\text { Group } \\
(\mathrm{N}=38)\end{array}$} & Correlation Coefficient & $0.381(* *)$ & 0.030 & 0.183 & -0.140 & $0.314(* *)$ & -0.001 & -0.198 \\
\hline & Significance (2-tailed) & 0.001 & 0.792 & 0.107 & 0.218 & 0.005 & 0.990 & 0.081 \\
\hline & Correlation Coefficient & 0.003 & 0.226 & -0.202 & -0.020 & 0.176 & $0.328(* *)$ & 0.041 \\
\hline \multicolumn{2}{|c|}{ (B) Central White Matter } & NAA & mIns & $\mathrm{Cr}$ & Cho & $\mathrm{NAA} / \mathrm{Cr}$ & $\mathrm{mIns} / \mathrm{Cr}$ & $\mathrm{Cho} / \mathrm{Cr}$ \\
\hline \multirow{2}{*}{$\begin{array}{l}\text { Age } \\
(\mathrm{N}=49) \\
\text { Group } \\
(\mathrm{N}=49)\end{array}$} & Correlation Coefficient & $0.504(* *)$ & $0.297(* *)$ & 0.212 & 0.227 & $0.291(* *)$ & 0.171 & 0.047 \\
\hline & Significance (2-tailed) & 0.012 & 0.483 & 0.679 & 0.760 & 0.021 & 0.679 & 0.640 \\
\hline
\end{tabular}

(**) Correlation is significant at the 0.01 level.


Figure 3. Box plots showing the different brain metabolite concentrations (median, 25th and 75th percentiles, and SD) in deep gray matter $(A)$ and central white matter $(B)$, grouped according to the severity of mental retardation in mild, moderate, and severe DD. $(C$ and $D$ ) Corresponding metabolite ratios in deep gray and central white matter, respectively. The larger SDs for NAA and mIns are partially due to greater variations in concentrations with age.

tecting cerebral metabolic derangements. This is especially important in view of the low yield of positive imaging findings in these children. Therefore, we were interested in whether there is a correlation between the concentrations of the various cerebral metabolites and the mental performance of these children and whether MRS adds significantly to the neuroradiologic work-up. Of special interest to us was whether NAA could be used as a marker for neurofunctional integrity of the brain and whether DD and intellectual deficit are reflected in reduced concentrations of NAA or any other cerebral metabolite measured noninvasively with proton MRS.

To our knowledge, two other research groups have addressed the same question measuring metabolite ratios of NAA/Cho and NAA/Cr, respectively $(36,37)$. In contrast, we used quantitative short echo-time proton MRS with calibration measurements; corrections for cerebrospinal fluid water contamination (partial volume effect); and baseline characterizations yielding $\mathrm{mM}$ concentrations of NAA, $\mathrm{Ch}, \mathrm{Cr}$, and mIns (40). In addition, we calculated metabolite ratios for comparison with data from other research groups. However, using
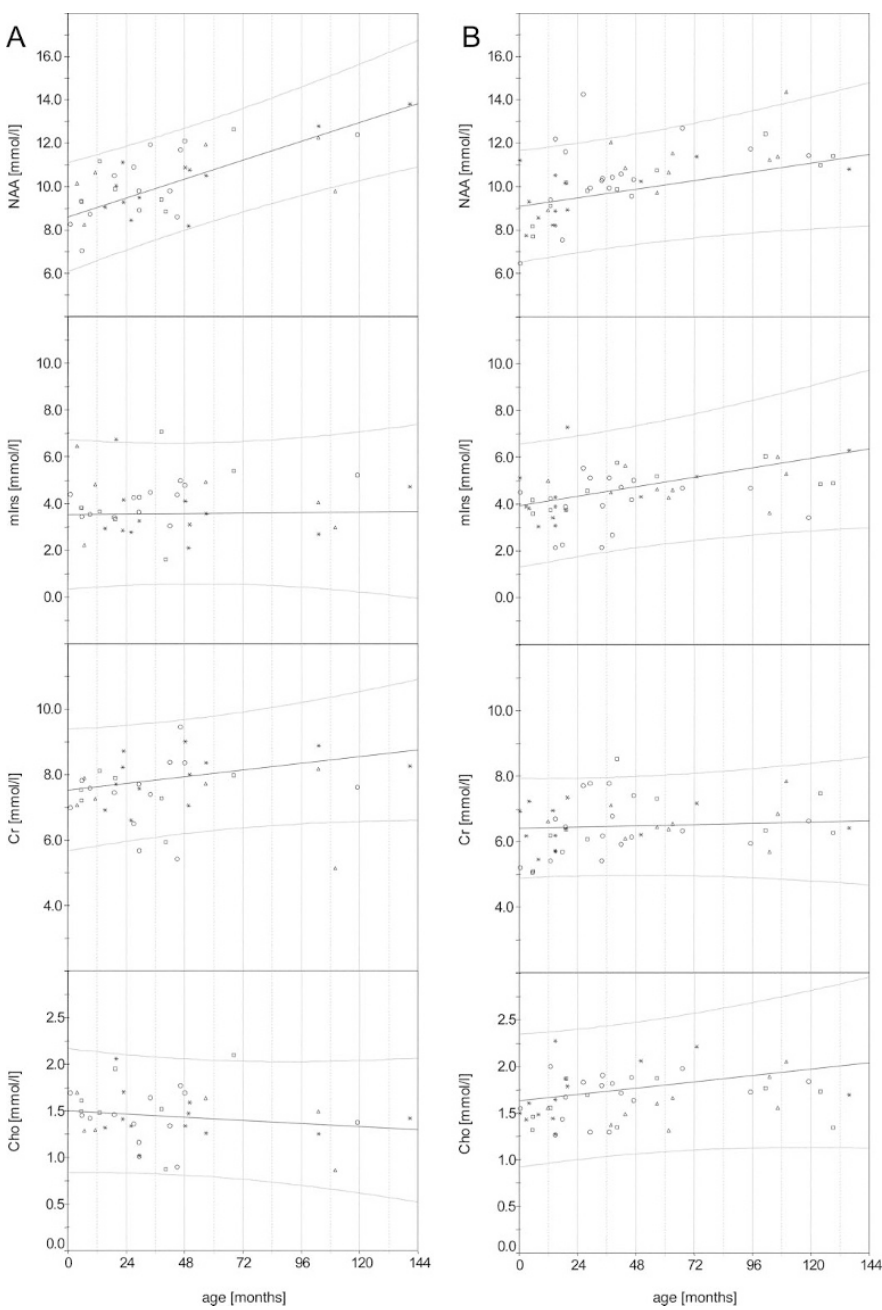

Figure 4. Individual concentrations of NAA, mIns, $\mathrm{Cr}$, and Cho of the three groups of children with mental retardation ( $\square$, mild DD;, moderate DD; $\triangle$, severe DD) measured in deep gray matter $(A)$ and in central white matter $(B)$. The solid and dotted lines represent the fitted concentrations and the 95\% confident limits from the control group (*).

metabolite ratios, there is a great uncertainty in whether an observed difference is due to changes in the nominator or rather (and more pronounced) to changes in the denominator; e.g. comparing the two spectra from children of $5 \mathrm{y}$ of age in the paper of Filippi et al. (37) (Fig. 3 in their paper), one can argue that the difference between the child with DD and the healthy 
control child is due to a higher concentration of Cho or $\mathrm{Cr}$ in the former rather than a reduced concentration of NAA.

Nevertheless, in the age range above $2 \mathrm{y}$, Filippi et al. (37) found significantly reduced ratios of NAA/Cr and $\mathrm{Cho} / \mathrm{Cr}$, and Hashimoto et al. (36) reported lower NAA/Cho ratios when comparing children with DD and healthy control subjects. We cannot corroborate these findings among our children with mild, moderate, or even severe mental retardation. Moreover, of the NAA concentrations from the four children with DD that are lying just outside the $95 \%$ confident limits, three are above (in white matter) and one is below the normal range (in gray matter; Fig. 4).

In the past, researchers have described maturational changes of brain metabolite concentrations. In particular, an agedependent increase of the total concentration of NAA in cerebral gray and white matter with normal brain development has been found predominantly during the first 3 y of life $(15,17,39,42)$. Here, we corroborate these findings and describe a rise of the NAA concentration with postnatal age (Fig. 4). Given that NAA is often called a "neuronal marker," the question remains how these changes in NAA concentration should be interpreted, e.g. a rise in NAA concentration in the early maturing brain cannot reflect a parallel increase in the number of neurons as neuronal proliferation ends before birth and almost no neurogenesis occurs in the mature brain, yet regressive processes start to prune neuronal and synaptic density around birth (43-45). Therefore, the observed changes in the concentration of NAA in gray and white matter during normal brain maturation might signify the development of synaptic terminals, dendritic arborizations, the increase in axonal diameter, and the progress of myelination (46-50). Canavan's disease is associated with high intracellular concentrations of NAA, which reflects neither increased neuronal density nor improved neuronal function. Instead, children with Canavan's disease unequivocally have mental retardation. Moreover, we recently reported on the total absence of NAA and NAAG in the entire brain of a 3-y-old boy with moderately severe neurodevelopmental retardation and slightly delayed myelination on MRI. We concluded that the concentration of NAA cannot a priori be taken as an indicator of functional integrity of the brain (51).

There are some limitations to our study. We selected two regions for single voxel spectroscopy, deep gray matter nuclei and parietofrontal white matter, because the former are important relay stations for cortical interactions and the latter harbors critical connections for sensorimotor and higher brain functions. Nevertheless, it cannot be excluded that differences may have been detected had measurements been done in other anatomic areas. Still, our areas are well suited because of little partial volume effects with cerebrospinal fluid or other brain structures. In addition, similar areas were used by others; therefore, the results can be compared.

Taken together, the results of our study indicate that there is no correlation between the concentrations of brain metabolites and the developmental achievement of a child. Moreover, NAA does not signify intellectual performance per se, because in the evaluation of a child with DD, one might encounter normal, low, or even elevated concentrations of NAA in the brain and there is no a priori correlation between NAA and intellectual performance. However, under certain circumstances, NAA is a neuronal marker, i.e. it signifies disintegration of neural tissue in diseases for which we know or assume that in the premorbid state there was a normal concentration of NAA in the brain and that the disease encountered is accompanied by neuronal cell death, synaptic destruction, or demyelination, such as Alzheimer dementia, multiple sclerosis, hypoxic-ischemic encephalopathies, and brain atrophy, to name a few.

There is, however, somewhat conflicting information on microstructural changes and counts of neurons and synapses and on dendritic spine dysgenesis in the cerebral cortex of adult patients with mental retardation (52) versus in that of children with DD (53-56). Future studies with newer MR techniques such as diffusion tensor imaging and chemical shift imaging might bring more information on microstructural and metabolic changes in the living brain of children with DD.

\section{CONCLUSION}

Using quantitative 1H-MRS, we demonstrated in the present study that children with unexplained DD and normal MRI findings usually have normal, age-appropriate concentrations of brain metabolites, especially NAA, Cho, $\mathrm{Cr}$, and mIns, when compared with age-matched healthy control children. Except for the unusual event of detecting new unexpected metabolic diseases in children with DD and only marginal changes in MRI $(51,57)$, we believe that proton spectroscopy usually adds little additional information to the neuroradiologic work-up and that in children with DD, the concentration of NAA in the brain as neuronal marker has to be taken with care.

\section{REFERENCES}

1. Aicardi J 1998 The etiology of developmental delay. Semin Pediatr Neurol 5:15-20

2. Shevell MI 1998 The evaluation of the child with a global developmental delay. Semin Pediatr Neurol 5:21-26

3. Curry CJ, Stevenson RE, Aughton D, Byrne J, Carey JC, Cassidy S, Cunniff C, Graham JM Jr, Jones MC, Kaback MM, Moeschler J, Schaefer GB, Schwartz S, Tarleton J, Opitz J 1997 Evaluation of mental retardation: recommendations of a Consensus Conference: American College of Medical Genetics. Am J Med Genet 72:468-477

4. Battaglia A, Bianchini E, Carey JC 1999 Diagnostic yield of the comprehensive assessment of developmental delay/mental retardation in an institute of child neuropsychiatry. Am J Med Genet 82:60-66

5. Majnemer A, Shevell MI 1995 Diagnostic yield of the neurologic assessment of the developmentally delayed child. J Pediatr 127:193-199

6. Shevell MI, Majnemer A, Rosenbaum P, Abrahamowicz M 2001 Etiologic determination of childhood developmental delay. Brain Dev 23:228-235

7. Shevell M, Ashwal S, Donley D, Flint J, Gingold M, Hirtz D, Majnemer A, Noetzel M, Sheth RD; Quality Standards Subcommittee of the American Academy of Neurology; Practice Committee of the Child Neurology Society 2003 Practice parameter: evaluation of the child with global developmental delay: report of the Quality Standards Subcommittee of the American Academy of Neurology and The Practice Committee of the Child Neurology Society. Neurology 60:367-380

8. Schaefer GB, Bodensteiner JB 1998 Radiological findings in developmental delay Semin Pediatr Neurol 5:33-38

9. Martin E, Grutter R, Boesch C 1990 In vivo NMR spectroscopy: investigation of brain metabolism in neonates and infants. Pediatrie 45:677-682

10. Yokochi K, Aiba K, Horie M, Inukai K, Fujimoto S, Kodama M, Kodama K 1991 Magnetic resonance imaging in children with spastic diplegia-correlation with the severity of their motor and mental abnormality. Dev Med Child Neurol 33:18-25

11. Truwit CL, Barkovich AJ, Koch TK, Ferriero DM 1992 Cerebral palsy: MR findings in 40 patients. AJNR Am J Neuroradiol 13:67-78

12. Demaerel P, Kingsley DP, Kendall BE 1993 Isolated neurodevelopmental delay in childhood: clinicoradiological correlation in 170 patients. Pediatr Radiol 23:29-33

13. Cunningham RD Jr 1996 Neuroimaging studies in children with developmental delay. J Pediatr 128:302 
14. Azzopardi D, Wyatt JS, Hamilton PA, Cady EB, Delpy DT, Hope PL, Reynolds EO 1989 Phosphorus metabolites and intracellular $\mathrm{pH}$ in the brains of normal and small for gestational age infants investigated by magnetic resonance spectroscopy. Pediatr Res 25:440-444

15. van der Knaap MS, van der Grond J, van Rijen PC, Faber JA, Valk J, Willemse K 1990 Age-dependent changes in localized proton and phosphorus MR spectroscopy of the brain. Radiology 176:509-515

16. Hashimoto T, Tayama M, Miyazaki M, Fujii E, Harada M, Miyoshi H, Tanouchi M, Kuroda Y 1995 Developmental brain changes investigated with proton magnetic resonance spectroscopy. Dev Med Child Neurol 37:398-405

17. Pouwels PJ, Brockmann K, Kruse B, Wilken B, Wick M, Hanefeld F, Frahm J 1999 Regional age dependence of human brain metabolites from infancy to adulthood as detected by quantitative localized proton MRS. Pediatr Res 46:474-485

18. Zimmerman RA, Wang ZJ 1997 The value of proton MR spectroscopy in pediatric metabolic brain disease. AJNR Am J Neuroradiol 18:1872-1879

19. Wang ZJ, Zimmerman RA 1998 Proton MR spectroscopy of pediatric brain metabolic disorders. Neuroimaging Clin N Am 8:781-807

20. Hashimoto T, Tayama M, Miyazaki M, Yoneda Y, Yoshimoto T, Harada M, Miyosh H, Tanouchi M, Kuroda Y 1997 Differences in brain metabolites between patients with autism and mental retardation as detected by in vivo localized proton magnetic resonance spectroscopy. J Child Neurol 12:91-96

21. Peden CJ, Rutherford MA, Sargentoni J, Cox IJ, Bryant DJ, Dubowitz LM 1993 Proton spectroscopy of the neonatal brain following hypoxic-ischaemic injury. Dev Med Child Neurol 35:502-510

22. Penrice J, Cady EB, Lorek A, Wylezinska M, Amess PN, Aldridge RF, Stewart A, Wyatt JS, Reynolds EO 1996 Proton magnetic resonance spectroscopy of the brain in normal preterm and term infants, and early changes after perinatal hypoxia-ischemia. Pediatr Res 40:6-14

23. Martin E, Buchli R, Ritter S, Schmid R, Largo RH, Boltshauser E, Fanconi S, Duc G, Rumpel H 1996 Diagnostic and prognostic value of cerebral 31P magnetic resonance spectroscopy in neonates with perinatal asphyxia. Pediatr Res 40:749-758

24. Cendes F, Caramanos Z, Andermann F, Dubeau F, Arnold DL 1997 Proton magnetic resonance spectroscopic imaging and magnetic resonance imaging volumetry in the lateralization of temporal lobe epilepsy: a series of 100 patients. Ann Neurol 42:737-746

25. Frahm J, Michaelis T, Merboldt KD, Hanicke W, Gyngell ML, Bruhn H 1991 On the $\mathrm{N}$-acetyl methyl resonance in localized $1 \mathrm{H}$ NMR spectra of human brain in vivo. NMR Biomed 4:201-204

26. Pouwels PJ, Frahm J 1997 Differential distribution of NAA and NAAG in human brain as determined by quantitative localized proton MRS. NMR Biomed 10:73-78

27. Baslow MH 2000 Functions of $\mathrm{N}$-acetyl-L-aspartate and $\mathrm{N}$-acetyl-L-aspartylglutamate in the vertebrate brain: role in glial cell-specific signaling. J Neurochem 75:453-459

28. Moffett JR, Namboodiri MA 1995 Differential distribution of N-acetylaspartylglutamate and N-acetylaspartate immunoreactivities in rat forebrain. J Neurocytol 24:409_ 433

29. Simmons ML, Frondoza CG, Coyle JT 1991 Immunocytochemical localization of $\mathrm{N}$-acetyl-aspartate with monoclonal antibodies. Neuroscience 45:37-45

30. Urenjak J, Williams SR, Gadian DG, Noble M 1992 Specific expression of Nacetylaspartate in neurons, oligodendrocyte-type-2 astrocyte progenitors, and immature oligodendrocytes in vitro. J Neurochem 59:55-61

31. Bhakoo KK, Pearce D 2000 In vitro expression of N-acetyl aspartate by oligodendrocytes: implications for proton magnetic resonance spectroscopy signal in vivo. J Neurochem 74:254-262

32. Barker PB $2001 \mathrm{~N}$-acetyl aspartate - a neuronal marker? Ann Neurol 49:423-424

33. Jung RE, Brooks WM, Yeo RA, Chiulli SJ, Weers DC, Sibbitt WL Jr 1999 Biochemical markers of intelligence: a proton MR spectroscopy study of normal human brain. Proc R Soc Lond B Biol Sci 266:1375-1379

34. Patel SH, Inglese M, Glosser G, Kolson DL, Grossman RI, Gonen O 2003 Wholebrain $\mathrm{N}$-acetylaspartate level and cognitive performance in HIV infection. AJNR Am J Neuroradiol 24:1587-1591
35. Brooks JC, Roberts N, Kemp GJ, Gosney MA, Lye M, Whitehouse GH 2001 A proton magnetic resonance spectroscopy study of age-related changes in frontal lobe metabolite concentrations. Cereb Cortex 11:598-605

36. Hashimoto T, Tayama M, Miyazaki M, Yoneda Y, Yoshimoto T, Harada M, Miyosh H, Tanouchi M, Kuroda Y 1995 Reduced N-acetylaspartate in the brain observed on in vivo proton magnetic resonance spectroscopy in patients with mental retardation. Pediatr Neurol 13:205-208

37. Filippi CG, Ulug AM, Deck MD, Zimmerman RD, Heier LA 2002 Developmental delay in children: assessment with proton MR spectroscopy. AJNR Am J Neuroradio 23:882-888

38. Largo R, Caflisch J 2001 Neuromotor development from kindergarten age to adolescence. In: Kalverboer A, Gramsbergen A (eds) Handbook on Brain and Behaviour in Human Development, pp. 883. Dodrecht, The Netherlands: Kluwer.

39. Kreis R, Ernst T, Ross B 1993 Development of the human brain: in vivo quantification of metabolite and water content with proton magnetic resonance spectroscopy. Magn Reson Med 30:424-437

40. Provencher S 1993 Estimation of metabolite concentrations from localized in vivo NMR spectra. Magn Reson Med 30:672-679

41. Henning J, Thiel T, Speck O 1997 Improved sensitivity to overlapping multiplet signals in in vivo proton spectroscopy using multi-echo volume selective (CPRESS) experiments. Magn Reson Med 37:816-820

42. Horska A, Kaufmann WE, Brant LJ, Naidu S, Harris JC, Barker PB 2002 In vivo quantitative proton MRSI study of brain development from childhood to adolescence. J Magn Reson Imaging 15:137-143

43. Cowan WM, Fawcett JW, O'Leary DD, Stanfield BB 1984 Regressive events in neurogenesis. Science 225:1258-1265

44. Oppenheim RW, Schwartz LM, Shatz CJ 1992 Neuronal death, a tradition of dying. J Neurobiol 23:1111-1115

45. Kornack DR, Rakic P 2001 Cell proliferation without neurogenesis in adult primate neocortex. Science 294:2127-2130

46. Huttenlocher PR, De Courten C, Garey LJ, Van der Loos H 1982 Synaptic development in human cerebral cortex. Int J Neurol 16-17:144-154

47. Rakic P, Bourgeois JP, Eckenhoff MF, Zecevic N, Goldman-Rakic PS 1986 Concurrent overproduction of synapses in diverse regions of the primate cerebral cortex. Science $232 \cdot 232-235$

48. Catsicas S, Thanos S, Clarke PG 1987 Major role for neuronal death during brain development: refinement of topographical connections. Proc Natl Acad Sci USA 84:8165-8168

49. Kinney HC, Brody BA, Kloman AS, Gilles FH 1988 Sequence of central nervous system myelination in human infancy. II. Patterns of myelination in autopsied infants. J Neuropathol Exp Neurol 47:217-234

50. Moffett JR, Namboodiri MA, Neale JH 1993 Enhanced carbodiimide fixation for immunohistochemistry: application to the comparative distributions of $\mathrm{N}$ acetylaspartylglutamate and $\mathrm{N}$-acetylaspartate immunoreactivities in rat brain. J Histochem Cytochem 41:559-570

51. Martin E, Capone A, Schneider J, Hennig J, Thiel T 2001 Absence of Nacetylaspartate in the human brain: impact on neurospectroscopy? Ann Neurol 49:518-521

52. Cragg BG 1975 The density of synapses and neurons in normal, mentally defective ageing human brains. Brain 98:81-90

53. Huttenlocher PR 1974 Dendritic development in neocortex of children with mental defect and infantile spasms. Neurology 24:203-210

54. Huttenlocher PR 1975 Synaptic and dendritic development and mental defect. UCLA Forum Med Sci (18):123-140

55. Purpura DP 1974 Dendritic spine "dysgenesis" and mental retardation. Science 186:1126-1128

56. Huttenlocher PR 1991 Dendritic and synaptic pathology in mental retardation. Pediatr Neurol 7:79-85

57. Stockler S, Holzbach U, Hanefeld F, Marquardt I, Helms G, Requart M, Hanicke W, Frahm J 1994 Creatine deficiency in the brain: a new, treatable inborn error of metabolism. Pediatr Res 36:409-413 